\title{
Promoted liquid-phase hydrodechlorination of chlorophenol over Raney Ni via controlling base: Performance, mechanism, and application
}

\author{
Xuanxuan Ma ${ }^{\text {a, }}$, Sujing Liu ${ }^{a}$, Ying Liu ${ }^{a}$, Xiaoqiang Li $^{\text {b }}$, Qing Li $^{c}$, Guodong Gu ${ }^{\text {e, }}$ \\ Chuanhai Xia ${ }^{\text {a, * }}$ \\ ${ }^{a}$ The Institute for Advanced Study of Coastal Ecology, School of Resources and Environmental Engineering, Ludong University, Yantai, 264025, China \\ b School of Environment and Materials Engineering, Yantai University, Yantai, 264005, China \\ c Yantai Institute of Coastal Zone Research, Chinese Academy of Sciences, Yantai, 264003, China \\ ${ }^{\mathrm{d}}$ Fujian Provincial Colleges and University Engineering Research Center of Solid Waste Resource Utilization, Longyan University, Longyan, 364012, China \\ e Alliance Pharma, Inc. 17 Lee Boulevard Malvern, PA, 19355, USA
}

\section{H I G H L I G H T S}

- Base and its addition amount influence the HDC reactivity of chlorophenol over Raney Ni.

- The mechanism for promoted effect of base is elucidated by characterization techniques.

- Promising bases and their optimal amount are developed for the excellent HDC of chlorophenols.

- The stoichiometric amount of $\mathrm{NaOH}$ enables Raney Ni to possess higher stability.

\section{A R T I C L E I N F O}

\section{Article history:}

Received 4 August 2019

Received in revised form

15 October 2019

Accepted 22 October 2019

Available online 25 October 2019

Handling Editor: Jun Huang

\section{Keywords:}

Base

Promote

Chlorophenol

Hydrodechlorination (HDC)

Raney $\mathrm{Ni}$
G R A P H I C A L A B S T R A C T

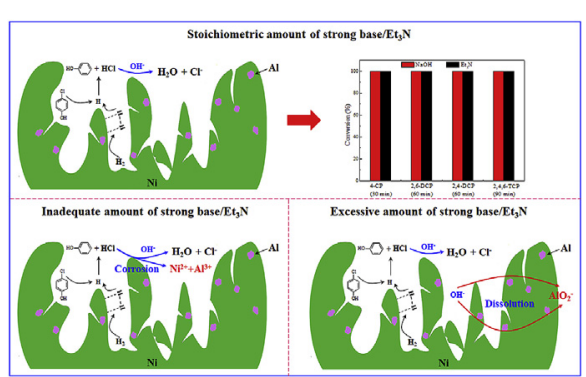

\begin{abstract}
A B S T R A C T
The potential effect of base on Raney Ni-catalyzed hydrodechlorination (HDC) of chlorophenol was studied. Compared to weak inorganic bases, strong inorganic bases $(\mathrm{NaOH}$ and $\mathrm{KOH})$ and triethylamine $\left(\mathrm{Et}_{3} \mathrm{~N}\right)$ were more favorable to promote Raney Ni-catalyzed HDC reaction. Moreover, a stoichiometric amount of $\mathrm{NaOH} / \mathrm{Et}_{3} \mathrm{~N}$ was found to be optimal for the HDC reaction, and up to $100 \%$ conversion of 4 chlorophenol was achieved within $30 \mathrm{~min}$. Catalyst characterization (SEM, EDXS, and XRD) combined with ICP-OES analysis were introduced to better understand the mechanism for the promoted effect of base on the HDC reaction. The results showed that the optimal amount of strong inorganic bases and $\mathrm{Et}_{3} \mathrm{~N}$ efficiently eliminated $\mathrm{HCl}$ corrosion to Raney $\mathrm{Ni}$, greatly reduced the active phase $\mathrm{Ni}$ and $\mathrm{Al}$ leaching, and avoided collapse of the catalyst framework. Based on the mechanism, the best bases and their optimal amount were developed for further disposal of polychlorinated phenols, and excellently stepwise HDC of polychlorinated phenols was achieved. Recycling tests showed that Raney Ni could be reused at least 5 times for the HDC reaction with the stoichiometric amount of $\mathrm{NaOH}$, which was a promising option for the HDC of wastewater containing chlorophenols over Raney Ni.
\end{abstract}

(c) 2019 Published by Elsevier Ltd.

\footnotetext{
* Corresponding author.

E-mail address: chxia_ldu@163.com (C. Xia).
} 


\section{Introduction}

Chlorophenols (CPs) are a class of significant pollutants in wastewater effluents since they are used extensively in the manufacture of germicides, fungicides, herbicides, pesticide, and wood protectors (Ge et al., 2017). Owing to their wide application and physicochemical properties, chlorophenols have been detected in groundwater, sediments, soil, and organisms (Shu et al., 2019; Zhao et al., 2017). Some chlorophenols are now listed as priority pollutants due to their high toxicity, low biodegradability, potential carcinogenic, teratogenic, or mutagenic, and persistence in the environment (Liu et al., 2019). Therefore, it is a major environmental challenge to develop an effective technique for the abatement of chlorophenols, which must be treated before discharging into the environment.

At present, numerous methods like physical method (Madannejad et al., 2018), biological method (Song et al., 2019), incineration (Peng et al., 2016), advanced oxidation processes (Li et al., 2019; Luo et al., 2018; Zhou et al., 2018), zero-valent metal reduction (Duan et al., 2016; Yang et al., 2017; Zheng et al., 2019), catalytic hydrodechlorination (HDC) (Jadbabaei et al., 2017; Ma et al., 2015; Xiong et al., 2018), etc have been applied for the elimination of chlorophenols. However, harsh reaction conditions and/or special facilities are often required in these methods, many of which are high-cost and will generate even more toxic byproducts (Guan et al., 2019; Madannejad et al., 2018; Zhao et al., 2018). Among these methods, catalytic HDC is a more prospective detoxifying technologies due to low-energy demands and the fact that the highly toxic chlorophenols are effectively transformed into less harmful products, reducing dramatically their ecotoxicity (Pizarro et al., 2017; Wu et al., 2012; Xiong et al., 2018). Liquidphase HDC of chlorophenols has been effectively catalyzed with supported noble metal (Rh, Au, Pt, Pd, etc.) catalysts (Descorme, 2017; Keane, 2011; Pizarro et al., 2015; Rong et al., 2013; Zhou et al., 2016). However, the high cost of these noble metal catalysts restricts their wide application in the HDC of chlorophenols (Xu et al., 2012). In this context, Raney Ni represent a promising option in catalytic HDC of chlorophenols due to its cost inexpensive and high resistance to halogen poisoning (Munoz et al., 2016). Moreover, Raney Ni possesses outstanding activity in catalytic HDC of chlorinated organic compounds under mild conditions (Ma et al., 2015; Zinovyev et al., 2007; Zinovyev and Tundo, 2007).

During liquid-phase $\mathrm{HDC}, \mathrm{HCl}$ is produced and will poison the catalyst (Urbano and Marinas, 2001). Moreover, the poison of $\mathrm{HCl}$ to catalyst has been associated with active phase leaching, metal-Cl formation, support structural breakdown, and active phase oxidation (Cobo et al., 2008). Thus, various bases are usually introduced to minimize the catalyst deactivation and enhance stability (Ma et al., 2015). Yet, the addition of bases has showed both beneficial and negative effects on catalyst activity and/or stability (de Pedro et al., 2011). In Pd-catalyzed HDC of 2,4-dichlorophenol, the HDC activity and selectivity exhibited different $\mathrm{pH}$ dependent, which was attributed to the lessening of $\mathrm{HCl}$ inhibition (Yuan and Keane, 2004b). Cobo et al. (2008) suggested that optimal amount of $\mathrm{NaOH}$ was required to avoid the active metal leaching and to reduce solid residues deposition on catalyst surface. Gómez-Quero et al. (2008) found that solution $\mathrm{pH}$ values determined the reactant/catalyst interaction, and then impacted on the HDC pathway of 2,4dichlorophenol over $\mathrm{Pd} / \mathrm{Al}_{2} \mathrm{O}_{3}$. Ordóñez et al. (2010) studied Pdcatalyzed HDC of trichloroethylene in wastewaters, and found that $\mathrm{Na}_{2} \mathrm{CO}_{3}$ largely increased stability of the catalyst. In the HDC of 4-chlorophenol over $\mathrm{Pd} / \mathrm{Al}_{2} \mathrm{O}_{3}$, de Pedro et al. (2011) attributed a stronger deactivation upon time on stream to the formation of palladium chloride complexes. We previously proposed that the action and existing species of $\mathrm{Et}_{3} \mathrm{~N}$ in reaction medium determined Raney Ni catalyzed HDC reactivity/selectivity of chlorophenols (Ma et al., 2010). Noticeably, most of these studies focused on the influence of base on Pd-catalyzed HDC reactions. So far, research on the effect of bases on Raney Ni-catalyzed HDC reaction is limited. Moreover, the mechanism of base effect on Raney Ni-catalyzed HDC is still not well established.

Herein, we explore the potential effect of base on Raney Nicatalyzed HDC of chlorophenol in aqueous solution. In this paper, 4-chlorophenol was selected as a representative pollutant to evaluate the influence of different bases and base amount on Raney $\mathrm{Ni}$ catalyzed HDC reaction. With the aid of ICP-OES analysis and characterization techniques (SEM, EDXS, and XRD), the mechanism for the potential effect of base was elucidated. Moreover, the application on the HDC of polychlorinated phenols over Raney $\mathrm{Ni}$ were further investigated. Finally, this work is expected to offer useful information for the HDC of wastewater containing chlorophenols.

\section{Experimental}

\subsection{Materials}

Raney Ni was acquired from Dalian Tongyong Chemical Co., Ltd. The catalyst was used as received without pre-treated and was kept in water-sealing storage before each experiment (Physicochemical properties are provided in Table S1 of Supplementary Material). The chemicals were all listed in Supplementary Material (Text SM1).

\subsection{General catalytic HDC procedure}

Catalytic HDC reaction was operated in a $100 \mathrm{~mL}$ three-neck flask under a constant volumetric $\mathrm{H}_{2}$ flow of $10 \mathrm{~mL} \mathrm{~min}^{-1}$ as our previous report (Ma et al., 2018). The experimental processes and conditions were provided in Supplementary Material (Text SM2). The $\mathrm{pH}$ of initial and final solutions was measured using an FE28standerd $\mathrm{pH}$ meter (METTLER-TOLEDO). The inductively coupled plasma-optical emission spectrometry (ICP-OES, Optima 7000 DV, Perkin Elmer) was employed to test the active phase leaching of Raney Ni.

\subsection{Analytical methods}

The reaction intermediates of chlorophenols were identified by Thermo Fisher ITQ-900 GC-MS (Gas Chromatograph-Mass Spectrometry) with a $30 \mathrm{~m} \mathrm{TG}-1701 \mathrm{MS}$ column $(0.25 \mathrm{~mm} \times 0.25 \mu \mathrm{m})$. The concentration of chlorophenols and their intermediate products were analyzed by Agilent-7890 A GC-FID (Gas ChromatographFlame Ionization Detector) equipped with a $30 \mathrm{~m}$ DB-1701 column $(0.32 \mathrm{~mm} \times 0.25 \mu \mathrm{m})$. The chromatographic conditions were given in Supplementary Material (Text SM3). The conversion was defined as Eq. (S1), while the HDC reactivity was evaluated using HDC rate, which was calculated as Eq. (S2).

\subsection{Catalyst characterizations}

The catalyst surface morphology and chemical elementals were analyzed using Hitachi S-4800 FE-SEM (Field Emission Scanning Electron Microscope) and an attached HORIBA EMAX Energy EX350 EDXS (Energy Dispersive X-ray Spectrometer) before and after the reaction. The X-ray diffraction (XRD) patterns were obtained by Shimadzu XRD-6100 (Cu K $\alpha, 40 \mathrm{kV}$, and $30 \mathrm{~mA})$, with $2 \theta$ ranged from $5^{\circ}$ to $80^{\circ}$. 


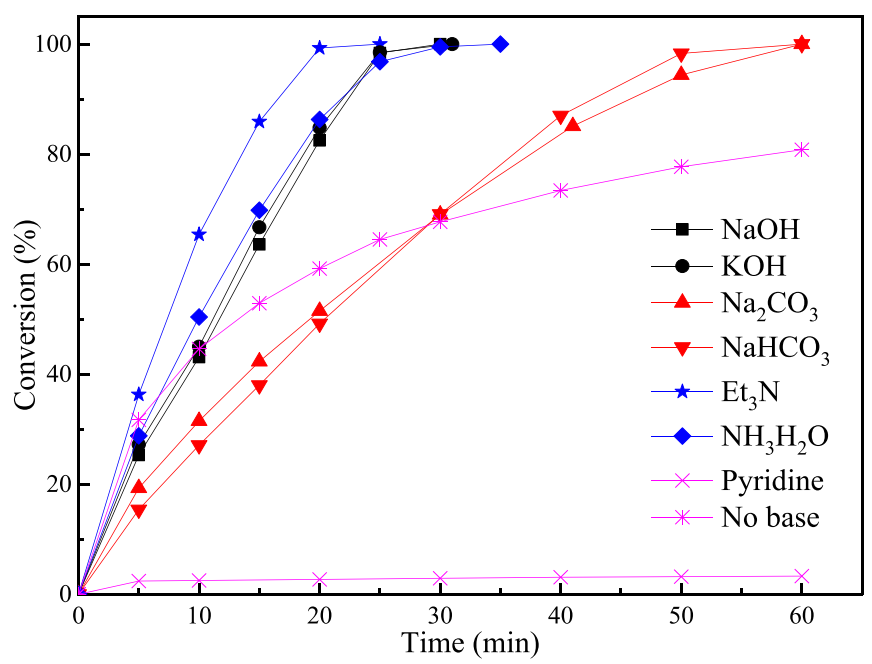

Fig. 1. The effect of various bases on Raney Ni-catalyzed HDC of 4-chlorophenol in aqueous medium. Reaction conditions: 4-chlorophenol ( $6.20 \mathrm{mmol})$, Raney Ni (0.12 g), $\mathrm{NaOH}(6.85 \mathrm{mmol}), \mathrm{KOH}(6.85 \mathrm{mmol}), \mathrm{Na}_{2} \mathrm{CO}_{3}(3.43 \mathrm{mmol}), \mathrm{NaHCO}_{3}(6.85 \mathrm{mmol})$, $\mathrm{NH}_{3} \cdot \mathrm{H}_{2} \mathrm{O}(6.85 \mathrm{mmol}), \mathrm{Et}_{3} \mathrm{~N}(6.85 \mathrm{mmol})$, and pyridine $(6.85 \mathrm{mmol}), \mathrm{H}_{2}: 10 \mathrm{~mL} \mathrm{~min}^{-1}$.

\section{Results and discussion}

\subsection{Effect of various bases on Raney Ni-catalyzed HDC of 4- chlorophenol}

Fig. 1 shows the conversion of 4-chlorophenol using Raney Ni versus reaction time in aqueous medium without base. As seen in Fig. 1, the conversion of 4 -chlorophenol reached $80.8 \%$ without base. During the HDC reaction, a stoichiometric amount of $\mathrm{HCl}$ was generated, and thus caused a significantly negative effect to Raney $\mathrm{Ni}$ (Yuan and Keane, 2004a). As a result, Raney Ni exhibited rather low catalytic activity, and 4-chlorophenol could not be completely hydrodechlorinated within $60 \mathrm{~min}$.

The time profiles for the HDC of 4-chlorophenol in aqueous medium of different bases are shown in Fig. 1. Notably, the HDC of 4-chlorophenol is promoted by base, and the HDC rate displays a strong correlation to bases in the following order: triethylamine $\left(\mathrm{Et}_{3} \mathrm{~N}\right)>$ sodium hydroxide $(\mathrm{NaOH}) \approx$ potassium hydroxide $(\mathrm{KOH})>$ ammonium hydroxide $\left(\mathrm{NH}_{3} \cdot \mathrm{H}_{2} \mathrm{O}\right)>$ sodium carbonate $\left(\mathrm{Na}_{2} \mathrm{CO}_{3}\right) \approx$ sodium bicarbonate $\left(\mathrm{NaHCO}_{3}\right)>$ pyridine. It can be seen from Fig. 1 that the best catalytic activity of Raney Ni was observed with $\mathrm{Et}_{3} \mathrm{~N}$. It is also noticed that Raney Ni possessed much stronger catalytic activities with strong inorganic bases than that with weak inorganic bases, which implied that strong inorganic bases were much better choices for the HDC reaction. Yet, the only negative effect on the HDC reaction occurred when pyridine was added, which should come from the catalyst poisoning caused by pyridine (Xia et al., 2003). In addition, massive agglomerations of Raney Ni were observed during the HDC reaction with pyridine. These results showed that strong inorganic bases and $\mathrm{Et}_{3} \mathrm{~N}$ were better options which possessed much higher promoted effect on Raney Ni-catalyzed HDC reaction.

In order to clarify the promoted effect of base on liquid-phase HDC reaction, we compared the $\mathrm{pH}$ of initial and final solutions (Table 1 ). The results showed that the byproduct $\mathrm{HCl}$ produced an increasing acidity from initial $\mathrm{pH} 6.63$ to final $\mathrm{pH} 2.30$ when the HDC reaction was carried out without base. In the case of the HDC process conducted with $\mathrm{NaOH}, \mathrm{KOH}, \mathrm{Na}_{2} \mathrm{CO}_{3}, \mathrm{NaHCO}_{3}, \mathrm{NH}_{3} \cdot \mathrm{H}_{2} \mathrm{O}$, $\mathrm{Et}_{3} \mathrm{~N}$, and pyridine, the obvious decrease of $\mathrm{pH}$ was also observed, which could be attributed to the production of $\mathrm{HCl}$. Nevertheless, the reaction solutions did not transform into the relatively strong acidic medium due to the base addition. This is in agreement with the observations reported by other scholars (Yuan and Keane, 2004b). Considering the HDC rate of 4-chlorophenol over Raney $\mathrm{Ni}$ with various bases (Table 1 ), a generally promoted effect on the $\mathrm{HDC}$ rate was obtained by adjusting the initial reaction medium $\mathrm{pH}$ from 7.62 to as high as 10.90 . In a word, the addition of various bases, except for pyridine, adjusted reaction medium to alkaline condition, which served to limit $\mathrm{HCl}$ poisoning to Raney $\mathrm{Ni}$. As a result, higher HDC rates of 4-chlorophenol over Raney $\mathrm{Ni}$ were achieved in alkaline medium provoked by the addition of various bases.

The active phase ( $\mathrm{Ni}$ and $\mathrm{Al}$ ) of Raney $\mathrm{Ni}$ are active metals and easy to be corroded, so the reaction medium $\mathrm{pH}$ has a considerable effect on the active phase leaching. To obtain further information about active phase leaching of Raney Ni, ICP-OES analysis was performed after the HDC reactions (Table 2). As expected, a large amount of $\mathrm{Ni}$ and $\mathrm{Al}$ leaching were observed, and their leaching amount were $72.76 \mathrm{mg}$ and $3.85 \mathrm{mg}$ when the HDC reaction was performed without base. The active phase $\mathrm{Ni}$ and $\mathrm{Al}$ leaching could be ascribed to the byproduct $\mathrm{HCl}$ and the subsequent corrosion effect. Similar results were found in the HDC of dioxins over Pd/ $\mathrm{Al}_{2} \mathrm{O}_{3}$ without base (Cobo et al., 2008). On the contrary, only a little amount of $\mathrm{Ni}$ and $\mathrm{Al}$ leaching were observed for the HDC reaction carried out in alkaline medium, as presented in Table 1. It would be reasonable to presume that the addition of bases suppressed the interaction of $\mathrm{HCl}$ with Raney $\mathrm{Ni}$ and largely reduced the active phase ( $\mathrm{Ni}$ and $\mathrm{Al}$ ) leaching.

To get more information on the promoted effect of bases, Raney $\mathrm{Ni}$ was characterized using SEM, EDXS, and XRD. Fig. 2 illustrates the SEM images of fresh and used catalysts. As shown in Fig. 2a, fresh Raney Ni possesses an obviously smooth surface morphology. Compared with the fresh catalyst, there are various thread-like structures appeared on surface morphology of the catalyst used in aqueous medium without base, which should be resulted from $\mathrm{HCl}$ corrosion. Fig. 2d-f show that surface morphologies of Raney Ni used in aqueous medium with $\mathrm{NaOH}, \mathrm{KOH}$, and $\mathrm{Et}_{3} \mathrm{~N}$ are almost the same as that of the fresh catalyst, revealing that the addition of

Table 1

The effect of various bases on Raney Ni-catalyzed HDC of 4-chlorophenol in aqueous medium.

\begin{tabular}{|c|c|c|c|c|c|c|}
\hline Base & Addition (mmol) & $\mathrm{pH}_{0}$ & $\mathrm{pH}_{1 \mathrm{~h}}$ & Ni leaching (mg) & Al leaching $(\mathrm{mg})^{\mathrm{a}}$ & HDC rate $\left(\min ^{-1}\right)$ \\
\hline No Base & 0 & 6.63 & 2.30 & 72.76 & 3.85 & 0.51 \\
\hline $\mathrm{NaOH}$ & 6.85 & 10.90 & 8.84 & 0.01 & 0.03 & 1.27 \\
\hline $\mathrm{KOH}$ & 6.85 & 10.46 & 7.23 & 0.33 & N.D. & 1.27 \\
\hline $\mathrm{Na}_{2} \mathrm{CO}_{3}$ & 3.43 & 9.14 & 5.72 & 0.51 & N.D. & 0.63 \\
\hline $\mathrm{NaHCO}_{3}$ & 6.85 & 7.62 & 5.71 & 0.80 & N.D. & 0.63 \\
\hline $\mathrm{NH}_{3} \cdot \mathrm{H}_{2} \mathrm{O}$ & 6.85 & 9.61 & 9.03 & 0.92 & 0.39 & 1.09 \\
\hline $\mathrm{Et}_{3} \mathrm{~N}$ & 6.85 & 10.05 & 8.45 & 0.01 & N.D. & 1.52 \\
\hline pyridine & 6.85 & 7.31 & 7.21 & 0.33 & N.D. & 0.02 \\
\hline
\end{tabular}

${ }^{a}$ N.D.: Not detected. 
Table 2

The effect of $\mathrm{NaOH} / \mathrm{Et}_{3} \mathrm{~N}$ amount on Raney Ni-catalyzed HDC of 4-chlorophenol in aqueous medium.

\begin{tabular}{|c|c|c|c|c|c|c|}
\hline Base & Addition (mmol) & $\mathrm{pH}_{0}$ & $\mathrm{pH}_{1 \mathrm{~h}}$ & Ni leaching (mg) & Al leaching $(\mathrm{mg})^{\mathrm{a}}$ & HDC rate $\left(\min ^{-1}\right)$ \\
\hline No Base & 0 & 6.63 & 2.30 & 72.76 & 3.85 & 0.51 \\
\hline \multirow[t]{4}{*}{$\mathrm{NaOH}$} & $3.12(0.5 \mathrm{NaOH})$ & 9.16 & 3.27 & 31.88 & 0.70 & 0.55 \\
\hline & $6.85(1.1 \mathrm{NaOH})$ & 10.90 & 8.84 & 0.01 & 0.03 & 1.27 \\
\hline & $13.70(2.2 \mathrm{NaOH})$ & 12.54 & 11.77 & $3.20 \times 10^{-3}$ & 4.02 & 0.53 \\
\hline & $27.40(4.4 \mathrm{NaOH})$ & 12.87 & 12.76 & 0.01 & 5.05 & 0.44 \\
\hline \multirow[t]{4}{*}{$\mathrm{Et}_{3} \mathrm{~N}$} & $3.12\left(0.5 \mathrm{Et}_{3} \mathrm{~N}\right)$ & 9.11 & 2.87 & 33.84 & 0.48 & 0.55 \\
\hline & $6.85\left(1.1 \mathrm{Et}_{3} \mathrm{~N}\right)$ & 10.05 & 8.44 & 0.01 & N.D. & 1.52 \\
\hline & $13.70\left(2.2 \mathrm{Et}_{3} \mathrm{~N}\right)$ & 10.77 & 9.95 & 0.04 & 0.75 & 1.90 \\
\hline & $27.40\left(4.4 \mathrm{Et}_{3} \mathrm{~N}\right)$ & 11.20 & 10.65 & 0.04 & 1.39 & 1.90 \\
\hline
\end{tabular}

a N.D.: Not detected.

$\mathrm{NaOH}, \mathrm{KOH}$, and $\mathrm{Et}_{3} \mathrm{~N}$ efficiently prevented $\mathrm{HCl}$ corrosion to the catalysts. Yet, surface morphology of the catalyst used in aqueous medium with $\mathrm{NH}_{3} \cdot \mathrm{H}_{2} \mathrm{O}$ has a laminated structure (Fig. $2 \mathrm{~g}$ ). Moreover, there are also some thread-like structures dispersed on surface morphology of the catalysts used in aqueous medium with $\mathrm{Na}_{2} \mathrm{CO}_{3}$ and $\mathrm{NaHCO}_{3}$ (Fig. 2h and i), which are similar to the observation without base. These results further suggested that the addition of $\mathrm{NH}_{3} \cdot \mathrm{H}_{2} \mathrm{O}, \mathrm{Na}_{2} \mathrm{CO}_{3}$, and $\mathrm{NaHCO}_{3}$ could not avoid $\mathrm{HCl}$ corrosion to the catalysts. According to these SEM images, the addition of $\mathrm{NaOH}, \mathrm{KOH}$, and $\mathrm{Et}_{3} \mathrm{~N}$ effectively prevented $\mathrm{HCl}$ corrosion to surface morphology of the catalysts (Fig. 2d-f), yet the addition of $\mathrm{NH}_{3} \cdot \mathrm{H}_{2} \mathrm{O}, \mathrm{Na}_{2} \mathrm{CO}_{3}$, and $\mathrm{NaHCO}_{3}$ could not (Fig. 2g-i).

To get surface elemental composition of Raney Ni, EDXS analyses were carried out (Fig. S1). The EDXS patterns implied that the addition of bases reduced the accumulation of $\mathrm{Cl}^{-}$on catalyst surface. Meanwhile, the elemental composition of catalyst surface changed after the HDC reaction. Further, XRD analysis of Raney Ni was performed (Fig. S2). The peaks at $2 \theta=44.5^{\circ}, 51.8^{\circ}$, and $76.3^{\circ}$ are corresponding to (1 111 ), (2 00 ), and (2 200 ) planes of nickel, respectively (Cheng et al., 2010). Only Ni peaks were found in the XRD patterns of Raney Ni used in aqueous medium with or without base. These results confirmed that no other crystal appeared on catalyst surface after the HDC reaction.

According to the above discussion, a possible mechanism for promoted effect of base on Raney Ni-catalyzed HDC reaction is suggested (Scheme 1). When Raney Ni-catalyzed HDC reaction was carried out in aqueous medium without base, the byproduct $\mathrm{HCl}$ resulted in an increasing acidity from near-neutral $\mathrm{pH}$ to strong acidic $\mathrm{pH}$, and the subsequent corrosion effect of $\mathrm{HCl}$ induced a large amount of $\mathrm{Ni}$ and $\mathrm{Al}$ leaching. As a result, catalytic activity of Raney Ni becomes lower and lower with the reaction time, and 4chlorophenol could not be completely hydrodechlorinated within 60 min (Fig. 1). The addition of various bases enabled the HDC reaction to be carried out in alkaline medium, neutralizing the byproduct $\mathrm{HCl}$ (Descorme, 2017). As the HDC reaction medium, water could prevent inorganic salts, which were produced by neutralization of $\mathrm{HCl}$ and bases, from depositing on catalyst surface (Ma et al., 2015). Accordingly, the bases such as $\mathrm{NaOH}, \mathrm{KOH}$, and $\mathrm{Et}_{3} \mathrm{~N}$ efficiently prevented $\mathrm{HCl}$ corrosion to surface morphology of Raney Ni (Fig. 2d-f), and avoided the active phase Ni and Al leaching (Table 2), and thus enabled the HDC rate of 4-chlorophenol to be rather high. Weak inorganic bases such as $\mathrm{NH}_{3} \cdot \mathrm{H}_{2} \mathrm{O}, \mathrm{Na}_{2} \mathrm{CO}_{3}$, and $\mathrm{NaHCO}_{3}$ could not efficiently avoid $\mathrm{HCl}$ corrosion to surface morphology of Raney Ni (Fig. $2 \mathrm{~g}-\mathrm{i}$ ), but they greatly reduced the active phase $\mathrm{Ni}$ and $\mathrm{Al}$ leaching (Table 1 ), and thus led to relatively lower HDC rate of 4-chlorophenol. Therefore, strong inorganic bases $(\mathrm{NaOH}$ and $\mathrm{KOH})$ and $\mathrm{Et}_{3} \mathrm{~N}$ were much better bases which possessed much higher promoted effect on Raney Ni-catalyzed HDC reaction.

\subsection{Effect of $\mathrm{NaOH}$ and $\mathrm{Et}_{3} \mathrm{~N}$ amount on Raney Ni-catalyzed $\mathrm{HDC}$ of 4-chlorophenol}

As mentioned above, the addition of various bases adjusted the reaction medium $\mathrm{pH}$, and thus affected surface morphology and active phase of Raney Ni, and enhanced the HDC reactivity of 4chlorophenol. Moreover, strong inorganic bases $(\mathrm{NaOH}$ and $\mathrm{KOH})$ and $\mathrm{Et}_{3} \mathrm{~N}$ were much better choices for Raney Ni-catalyzed HDC reaction. Thus, effect of $\mathrm{NaOH}$ and $\mathrm{Et}_{3} \mathrm{~N}$ amount on Raney $\mathrm{Ni}$ catalyzed HDC reaction was further studied to ascertain the optimal amount of base in the HDC reaction (Fig. 3).

Fig. 3A shows Raney Ni-catalyzed 4-chlorophenol conversion versus reaction time with different amount of $\mathrm{NaOH}$. When the amount of $\mathrm{NaOH}$ were $0 \mathrm{mmol}\left([\mathrm{NaOH}]_{0} /[\text { organic- } \mathrm{Cl}]_{0}=0\right.$, $0 \mathrm{NaOH}), 3.12 \mathrm{mmol}(0.5 \mathrm{NaOH}), 6.85 \mathrm{mmol}(1.1 \mathrm{NaOH}), 13.70 \mathrm{mmol}$ $(2.2 \mathrm{NaOH})$, and $27.40 \mathrm{mmol}(4.4 \mathrm{NaOH})$, the HDC rates of 4chlorophenol over Raney $\mathrm{Ni}$ are $0.51 \mathrm{~min}^{-1}, 0.55 \mathrm{~min}^{-1}, 1.27$ $\mathrm{min}^{-1}, 0.53 \mathrm{~min}^{-1}$, and $0.44 \mathrm{~min}^{-1}$, respectively (Table 2). This confirmed that the HDC rate of 4-chlorophenol increased with $\mathrm{NaOH}$ amount at low concentration and then began to decrease after an excessive amount of $\mathrm{NaOH}$ was added. Notably, the optimal HDC rate of 4-chlorophenol shows up in the reaction medium with $1.1 \mathrm{NaOH}$. Furthermore, the initial and final reaction medium $\mathrm{pH}$ was compared (Table 2). When the reaction medium $\mathrm{pH}$ changed from 9.16 to 10.90 , a promoted effect on the HDC rate of 4chlorophenol was noticed. Yet, an opposite trend was observed when the reaction medium $\mathrm{pH}$ was higher than 10.90. Also, the obvious decrease of $\mathrm{pH}$ was seen resulted from the production of $\mathrm{HCl}$ when the $\mathrm{HDC}$ reaction was performed with different $\mathrm{NaOH}$ amount. Even after the HDC reaction, the $\mathrm{pH}$ of the reaction medium with $2.2 \mathrm{NaOH}$ and $4.4 \mathrm{NaOH}$ were 11.77 and 12.76. This implied that the low HDC rates of 4-chlorophenol with $2.2 \mathrm{NaOH}$ and $4.4 \mathrm{NaOH}$ could not be ascribed to the corrosion effect of $\mathrm{HCl}$ to Raney Ni. Subsequently, ICP-OES analysis was carried out to evaluate $\mathrm{Ni}$ and $\mathrm{Al}$ leaching of Raney Ni (Table 2). The amount of active phase Ni leaching of Raney Ni during the HDC reaction was greatly reduced due to $\mathrm{NaOH}$ addition. Yet, with the amount of $\mathrm{NaOH}$ increased, the amount of active phase Al leaching of Raney $\mathrm{Ni}$ decreased to minima and then increased. In other words, the excessive amount of $\mathrm{NaOH}$ avoided active phase Ni leaching of Raney $\mathrm{Ni}$, but induced active phase Al leaching of the catalyst. During the HDC reaction, $\mathrm{NaOH}$ was used to neutralizing the byproduct $\mathrm{HCl}$, and thus stoichiometric amount of $\mathrm{NaOH}$ or more prevented the active phase Ni leaching caused by the interaction of $\mathrm{HCl}$ with the catalyst. However, the excessive amount of $\mathrm{NaOH}$ would lead to the high $\mathrm{pH}$, and thus induced dissolution of the active phase $\mathrm{Al}$ and could be expressed as follows.

$2 \mathrm{Al}+2 \mathrm{H}_{2} \mathrm{O}+2 \mathrm{OH}^{-} \rightarrow 2 \mathrm{AlO}_{2}^{-}+3 \mathrm{H}_{2} \uparrow$ 

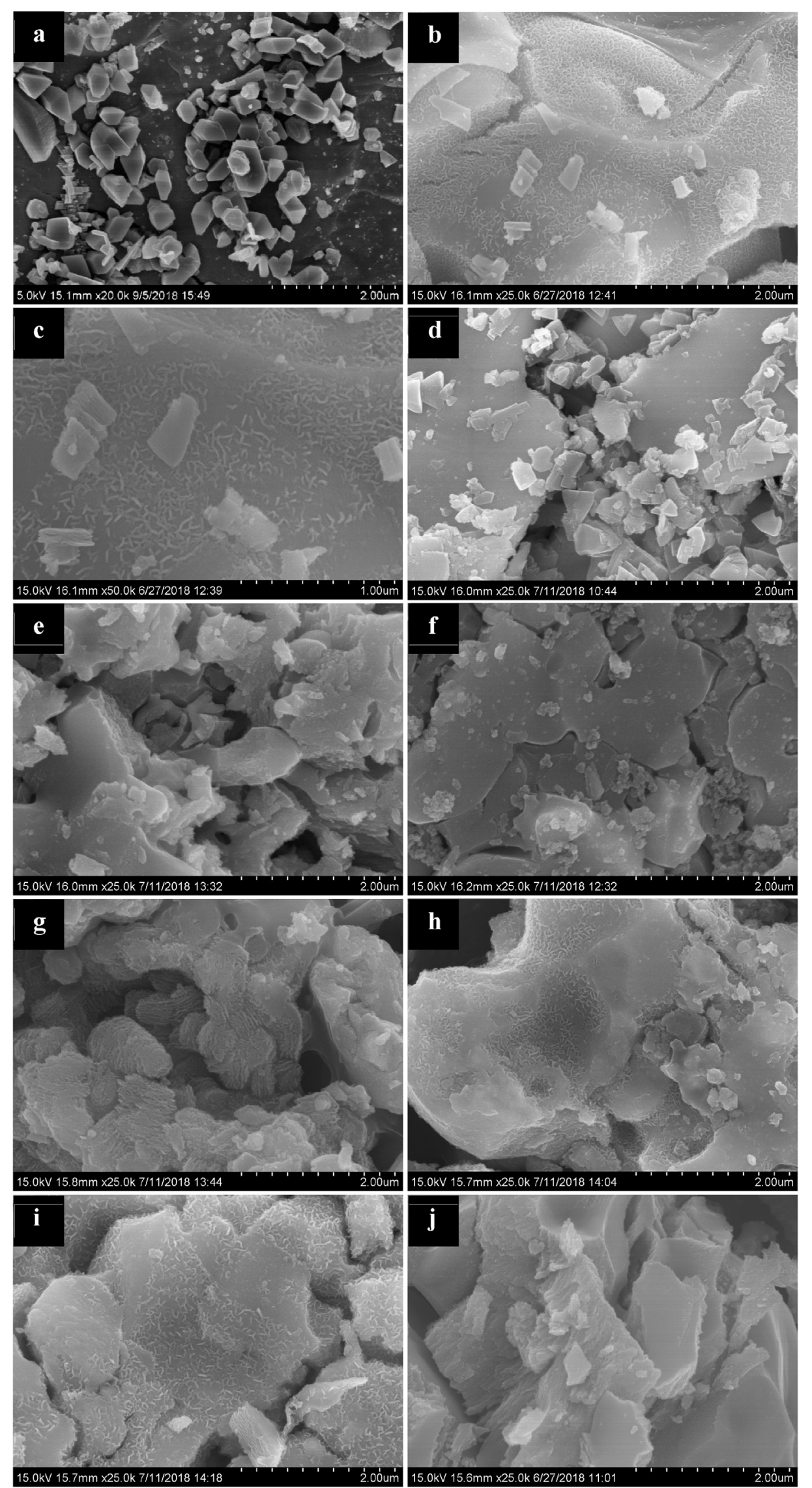

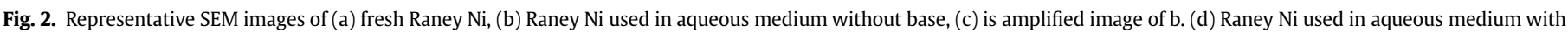

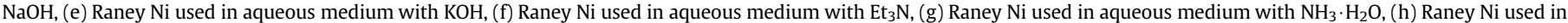
aqueous medium with $\mathrm{Na}_{2} \mathrm{CO}_{3}$, (i) Raney Ni used in aqueous medium with $\mathrm{NaHCO}_{3}$, and (j) Raney Ni used in aqueous medium with pyridine. 
Without Base
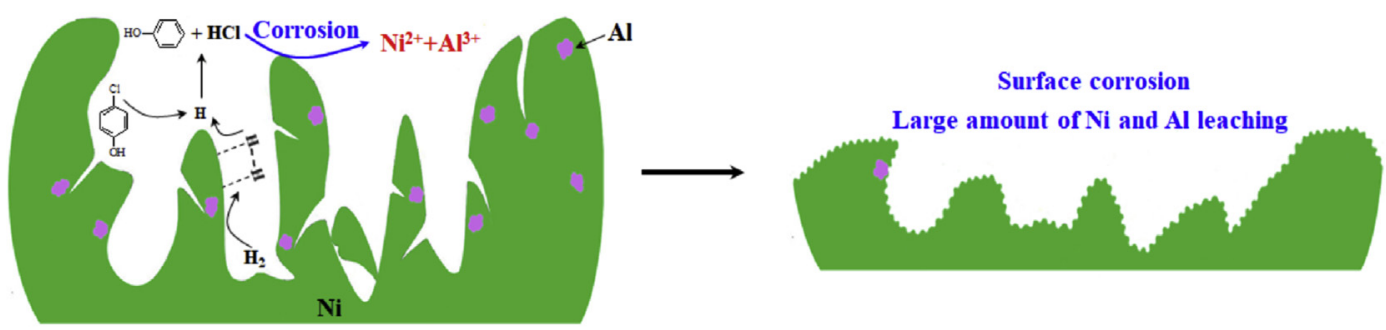

Strong inorganic bases
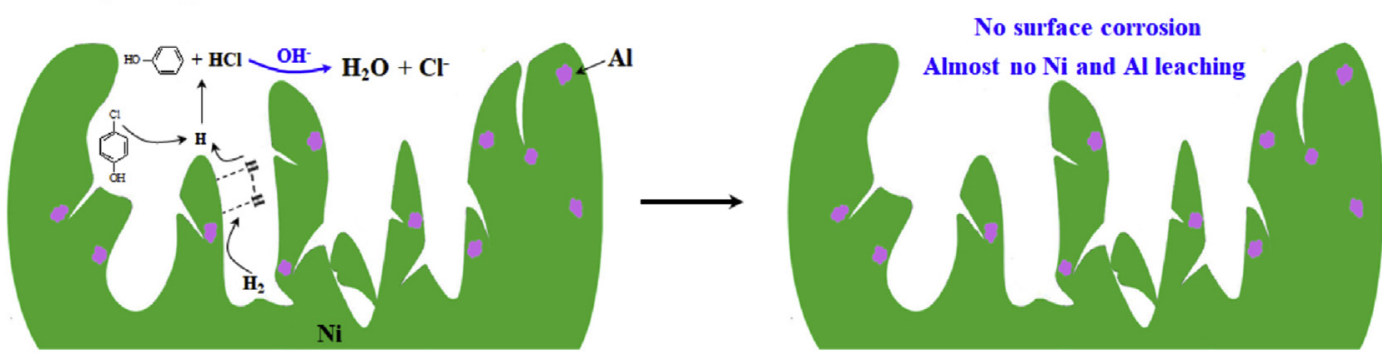

\section{Weak inorganic bases}
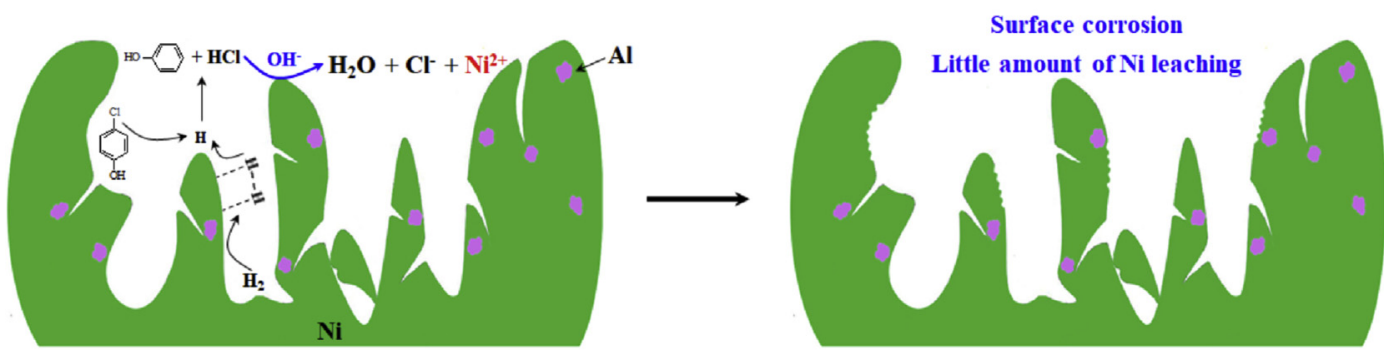

Scheme 1. Proposed mechanism for the effect of base addition on Raney Ni-catalyzed HDC of 4-chlorophenol.
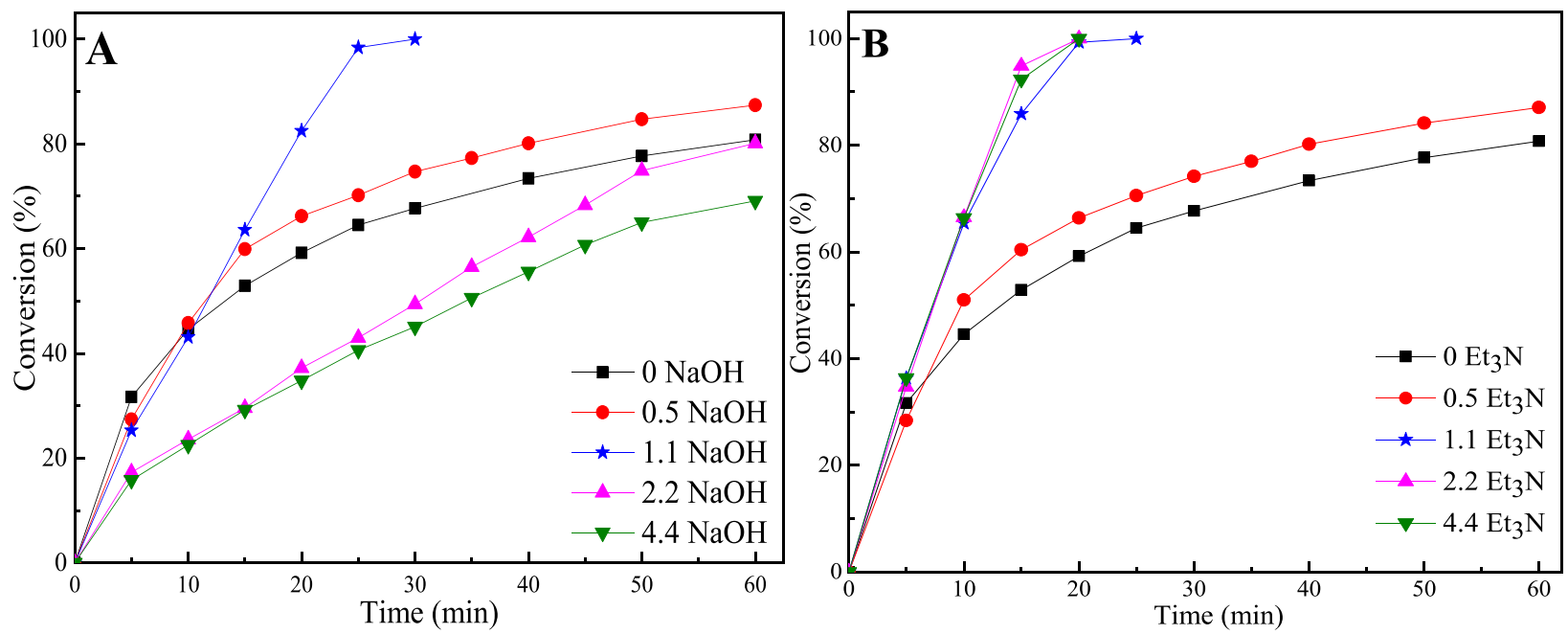

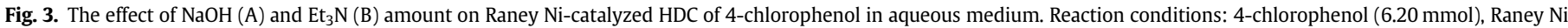
$(0.12 \mathrm{~g}), 0 \mathrm{NaOH} / \mathrm{Et}_{3} \mathrm{~N}(0 \mathrm{mmol}), 0.5 \mathrm{NaOH} / \mathrm{Et}_{3} \mathrm{~N}$ (3.12 mmol), $1.1 \mathrm{NaOH} / \mathrm{Et}_{3} \mathrm{~N}(6.85 \mathrm{mmol}), 2.2 \mathrm{NaOH} / \mathrm{Et}_{3} \mathrm{~N}(13.70 \mathrm{mmol}), a^{2} 4.4 \mathrm{NaOH} / \mathrm{Et}_{3} \mathrm{~N}(27.40 \mathrm{mmol}), \mathrm{H}_{2}: 10 \mathrm{~mL} \mathrm{~min}{ }^{-1}$.

On the other hand, the HDC of 4-chlorophenol was carried out where $\mathrm{Et}_{3} \mathrm{~N}$ addition amount of the reaction medium spanned the range $0-27.40 \mathrm{mmol}\left(\left[\mathrm{Et}_{3} \mathrm{~N}\right]_{0} /[\text { organic }-\mathrm{Cl}]_{0}=0-4.4\right)$ (Fig. $\left.3 \mathrm{~B}\right)$. As illustrated in Fig. 3B, the HDC rate of 4-chlorophenol increased with the increased $\mathrm{Et}_{3} \mathrm{~N}$ amount, and the highest $\mathrm{HDC}$ rate was observed with $2.2 \mathrm{Et}_{3} \mathrm{~N}$ and $4.4 \mathrm{Et}_{3} \mathrm{~N}$. After the HDC reaction, the $\mathrm{pH}$ of the 
reaction medium with $0.5 \mathrm{Et}_{3} \mathrm{~N}, 1.1 \mathrm{Et}_{3} \mathrm{~N}, 2.2 \mathrm{Et}_{3} \mathrm{~N}$, and $4.4 \mathrm{Et}_{3} \mathrm{~N}$ decreased to $2.87,8.44,9.95$, and 10.65 , respectively, with the initial $\mathrm{pH} 9.11,10.05,10.77$, and 11.20. An obvious decrease of $\mathrm{pH}$ with different $\mathrm{Et}_{3} \mathrm{~N}$ amount was also noticed after HDC reaction. Meanwhile, the amount of active phase $\mathrm{Ni}$ and $\mathrm{Al}$ leaching are given in Table 2. In the reaction medium with $0.5 \mathrm{Et}_{3} \mathrm{~N}, 1.1 \mathrm{Et}_{3} \mathrm{~N}, 2.2 \mathrm{Et}_{3} \mathrm{~N}$, and $4.4 \mathrm{Et}_{3} \mathrm{~N}$, the amount of active phase $\mathrm{Ni}$ leaching was greatly reduced due to $\mathrm{Et}_{3} \mathrm{~N}$ addition. Yet, the amount of active phase $\mathrm{Al}$ leaching decreased to minima and then increased with the amount of $\mathrm{Et}_{3} \mathrm{~N}$ increased. Likewise, $\mathrm{Et}_{3} \mathrm{~N}$ was added to neutralizing $\mathrm{HCl}$ (listed as the following Eq. (2) and Eq. (3)), and thus the stoichiometric amount of $\mathrm{Et}_{3} \mathrm{~N}$ or more prevented the active phase $\mathrm{Ni}$ leaching.

$\left(\mathrm{CH}_{3} \mathrm{CH}_{2}\right)_{3} \mathrm{~N}+\mathrm{H}_{2} \mathrm{O} \rightleftharpoons\left[\left(\mathrm{CH}_{3} \mathrm{CH}_{2}\right)_{3} \mathrm{NH}\right]^{+}+\mathrm{OH}^{-}$

$\mathrm{OH}^{-}+\mathrm{HCl} \rightarrow \mathrm{Cl}^{-}+\mathrm{H}_{2} \mathrm{O}$

However, the excessive amount of $\mathrm{Et}_{3} \mathrm{~N}$ also led to the high $\mathrm{pH}$ (Eq. (2)), and thus caused dissolution of active phase $\mathrm{Al}$ (Eq. (1)).

Further, characterization analyses (SEM, EDXS, and XRD) were carried out to evaluate the influence of $\mathrm{NaOH} / \mathrm{Et}_{3} \mathrm{~N}$ amount. The representative SEM images of fresh and used Raney Ni are shown in Fig. 4. Compared with fresh Raney Ni (Fig. 4a), there are various thread-like structures appeared on surface morphology of the catalyst used in aqueous medium without base. Similar phenomenon was observed in the case of the catalyst used in aqueous medium with $0.5 \mathrm{NaOH}$ (Fig. 4c). As mentioned above, surface morphology of Raney Ni used in aqueous medium with $1.1 \mathrm{NaOH}$ (Fig. 4d) is almost unchanged after the HDC reaction. Yet, surface morphology of Raney Ni used in aqueous medium with $2.2 \mathrm{NaOH}$ and $4.4 \mathrm{NaOH}$ (Fig. 4e and f) are different from that of the fresh catalyst. Moreover, it is evident that the inherent framework of Raney Ni was breakdown, which was resulted from dissolution of Al. These results suggested that an inadequate amount of $\mathrm{NaOH}$ could not efficiently prevent $\mathrm{HCl}$ corrosion to Raney $\mathrm{Ni}$, yet an excessive amount of $\mathrm{NaOH}$ would induce the dissolution of $\mathrm{Al}$, and thus lead to collapse of the catalyst framework. The stoichiometric amount of $\mathrm{NaOH}$ could eliminate $\mathrm{HCl}$ corrosion to Raney $\mathrm{Ni}$ and prevent collapse of the catalyst framework. On the other hand, surface morphology of Raney Ni used in aqueous medium with 0.5 $\mathrm{Et}_{3} \mathrm{~N}$ and $1.1 \mathrm{Et}_{3} \mathrm{~N}$ (Fig. $4 \mathrm{~g}$ and $\mathrm{h}$ ) are almost the same as those with $0.5 \mathrm{NaOH}$ and $1.1 \mathrm{NaOH}$. For Raney Ni used in aqueous medium with $2.2 \mathrm{Et}_{3} \mathrm{~N}$ and $4.4 \mathrm{Et}_{3} \mathrm{~N}$ (Fig. 4i and j), surface morphology of the catalysts become much rougher than that of the fresh catalyst, which might provide more active sites for interfacial HDC reaction. These SEM images further indicated that a stoichiometric amount of $\mathrm{Et}_{3} \mathrm{~N}$ could efficiently eliminate the $\mathrm{HCl}$ corrosion to Raney $\mathrm{Ni}$ and prevent collapse of the catalyst framework.

Meanwhile, surface elemental composition of Raney $\mathrm{Ni}$ was analyzed using EDXS (Fig. S3). These EDXS results further confirmed that a stoichiometric amount of $\mathrm{NaOH} / \mathrm{Et}_{3} \mathrm{~N}$ or more could inhibit the interaction of $\mathrm{HCl}$ with Raney Ni efficiently. Hence, the accumulation of $\mathrm{Cl}^{-}$on the catalyst surface decreased obviously with $\mathrm{NaOH} / \mathrm{Et}_{3} \mathrm{~N}$ amount increased. In addition, only Ni peaks were found in the XRD patterns of Raney $\mathrm{Ni}$ used in aqueous medium with different amount of $\mathrm{NaOH} / \mathrm{Et}_{3} \mathrm{~N}$ (Fig. S4). This implied that no other crystal appeared on catalyst surface after the HDC reaction.

Combining analyses of ICP-OES, SEM, EDXS, and XRD, the mechanism for the potential effect of $\mathrm{NaOH} / \mathrm{Et}_{3} \mathrm{~N}$ amount is proposed in Scheme 2. In aqueous medium with an inadequate amount of $\mathrm{NaOH} / \mathrm{Et}_{3} \mathrm{~N}$, the byproduct $\mathrm{HCl}$ caused significantly drop in the $\mathrm{pH}$ values as $\mathrm{HCl}$ could not be neutralized completely. The unreacted $\mathrm{HCl}$ would cause corrosion to Raney $\mathrm{Ni}$ and induced a large amount of $\mathrm{Ni}$ and $\mathrm{Al}$ leaching, and then led to deactivation of the catalyst. As a result, the catalytic activity of Raney Ni decreased as the HDC reaction proceeding in aqueous medium with an inadequate amount of base (Fig. 4). In aqueous medium with an excessive amount of $\mathrm{NaOH} / \mathrm{Et}_{3} \mathrm{~N}$, the $\mathrm{HDC}$ of 4-chlorophenol was carried out in strong alkaline medium throughout the reaction time, which prevented $\mathrm{HCl}$ corrosion to Raney $\mathrm{Ni}$ and avoided the active phase Ni leaching. However, the strong alkaline $\mathrm{pH}$ induced dissolution of $\mathrm{Al}$, leading to collapse of the catalyst framework. Moreover, the leaching amount of $\mathrm{Al}$ in aqueous medium with an excessive amount of $\mathrm{NaOH}$ was much more than that with $\mathrm{Et}_{3} \mathrm{~N}$. Also, massive collapse of the catalyst framework could be observed in aqueous medium with an excessive amount of $\mathrm{NaOH}$ compared to rougher surface morphology of Raney $\mathrm{Ni}$ with the excessive amount of $\mathrm{Et}_{3} \mathrm{~N}$ (Fig. 4). Thus, an excessive amount of $\mathrm{NaOH}$ showed a negative effect on the HDC rate, while the excessive amount of $\mathrm{Et}_{3} \mathrm{~N}$ still exhibited a promoted effect on the HDC rate. In this sense, a stoichiometric amount of $\mathrm{NaOH} / \mathrm{Et}_{3} \mathrm{~N}\left(1.1 \mathrm{NaOH} / \mathrm{Et}_{3} \mathrm{~N}\right)$ enabled the HDC reaction to be took place in the relatively mild alkaline medium, in which $\mathrm{HCl}$ corrosion to Raney $\mathrm{Ni}$ was eliminated and collapse of the catalysts framework was avoided. So, Raney Ni showed much stronger catalytic activity and accelerated the HDC of 4-chlorophenol when $1.1 \mathrm{NaOH} / \mathrm{Et}_{3} \mathrm{~N}$ was added. From a practical point of view, the catalytic activity of Raney $\mathrm{Ni}$ and the HDC reactivity of 4-chlorophenol can be efficiently regulated by means of adjusting the base and its amount.

\subsection{The application of $\mathrm{NaOH}$ and $\mathrm{Et}_{3} \mathrm{~N}$ in Raney $\mathrm{Ni}$-catalyzed $\mathrm{HDC}$ reaction}

Based on the above discussion, the mechanism of base effect was demonstrated and the best bases and their optimal amount were developed for the further application. Firstly, Raney Ni catalyzed HDC of polychlorinated phenols was established in aqueous medium with $1.1 \mathrm{NaOH} / \mathrm{Et}_{3} \mathrm{~N}$ (Fig. $5 \mathrm{~A}$, see more details in the Supporting Information, Fig. S5). As observed, 2,6-dichlorophenol and 2,4-dichlorophenol are hydrodechlorinated over Raney $\mathrm{Ni}$ into monochlorophenols, which can be further transformed into phenol. Moreover, 2,6-dichlorophenol and 2,4-dichlorophenol are the HDC intermediate products of 2,4,6-trichlorophenol, and then they are further converted to monochlorophenol, and finally to phenol over Raney Ni. Therefore, the HDC of 2,6-dichlorophenol, 2,4-dichlorophenol, and 2,4,6-trichlorophenol were stepwise processes (Scheme S1). Furthermore, it is important to remark that the excellent HDC of polychlorinated phenols over Raney Ni were achieved with $1.1 \mathrm{NaOH} / \mathrm{Et}_{3} \mathrm{~N}$. This confirmed that $1.1 \mathrm{NaOH} / \mathrm{Et}_{3} \mathrm{~N}$ was promising for efficient HDC of polychlorinated phenols over Raney Ni.

Then, the stability of Raney Ni was evaluated in the HDC reaction with $1.1 \mathrm{NaOH} / \mathrm{Et}_{3} \mathrm{~N}$. As shown in Fig. $5 \mathrm{~B}$, the conversion of 4chlorophenol with $1.1 \mathrm{NaOH}$ could reach $100 \%$ within 30 min after 5 cycles and gradually dropped to $73.9 \%$ in the 10 th run. Yet, the conversion of 4-chlorophenol with $1.1 \mathrm{Et}_{3} \mathrm{~N}$ was $100 \%$ at $30 \mathrm{~min}$ for the first 4 times but dropped to $56.3 \%$ in the 10th run. The phenomenon that the catalytic activity of Raney Ni gradually decreased when $1.1 \mathrm{Et}_{3} \mathrm{~N}$ was used in the HDC reaction could be attributed to the poison effect of $\mathrm{Et}_{3} \mathrm{~N} \cdot \mathrm{HCl}$ (Kume et al., 2008). These results demonstrated that Raney Ni possessed higher stability when 1.1 $\mathrm{NaOH}$ was used as proton scavenger, and could be reused for at least 5 times with a complete conversion of 4-chlorophenol. Therefore, a stoichiometric amount of $\mathrm{NaOH}$ was a best option for Raney Ni-catalyzed HDC reaction.

\section{Conclusions}

In the present study, we evaluated the promoted effect of base 

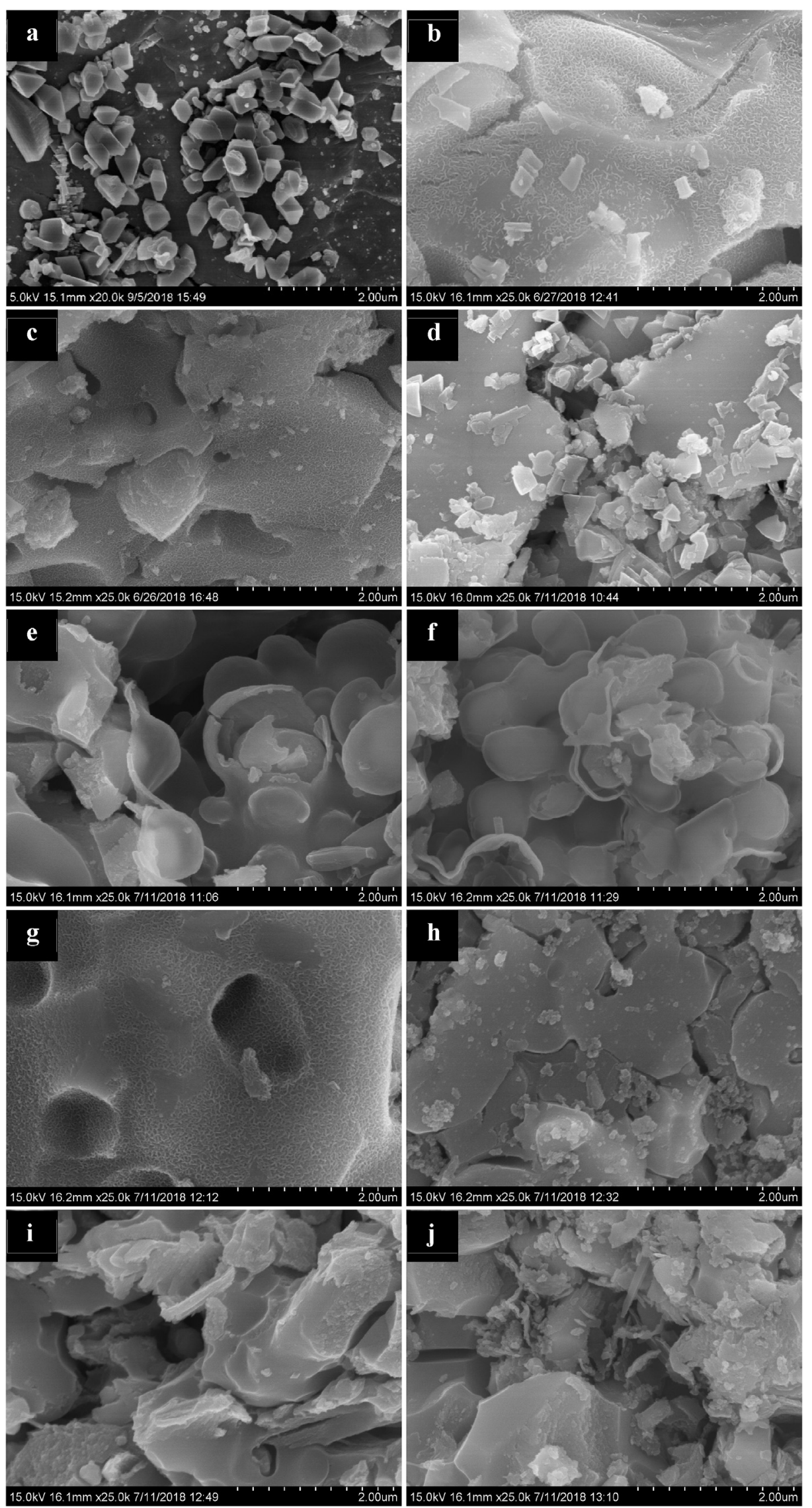

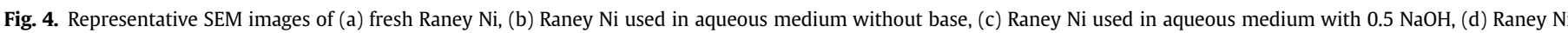

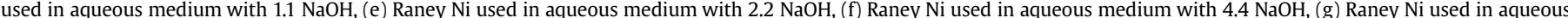

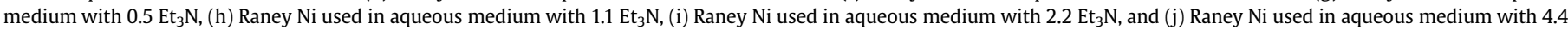
$\mathrm{Et}_{3} \mathrm{~N}$. 
Inadequate amount of $\mathrm{NaOH} / \mathrm{Et}_{3} \mathrm{~N}$
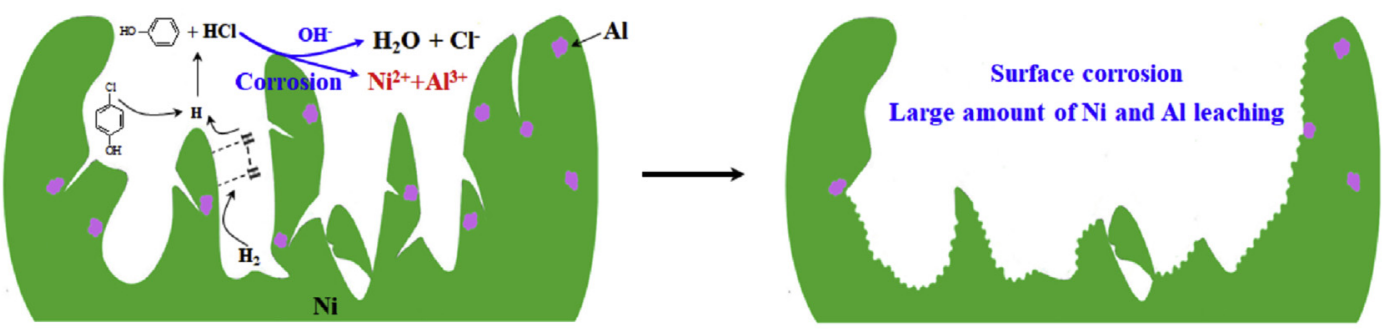

\section{Stoichiometric amount of $\mathrm{NaOH} / \mathrm{Et}_{3} \mathrm{~N}$}
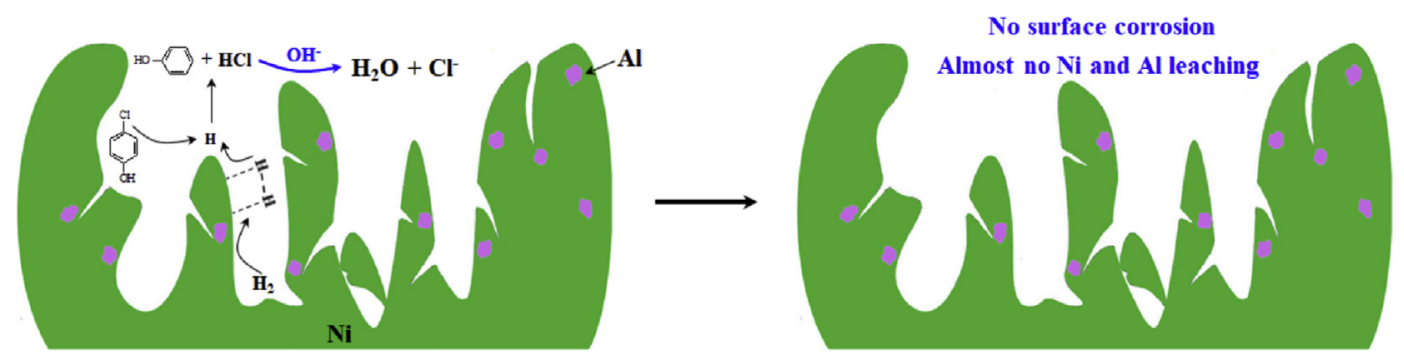

\section{Excessive amount of $\mathrm{NaOH} / \mathrm{Et}_{3} \mathrm{~N}$}
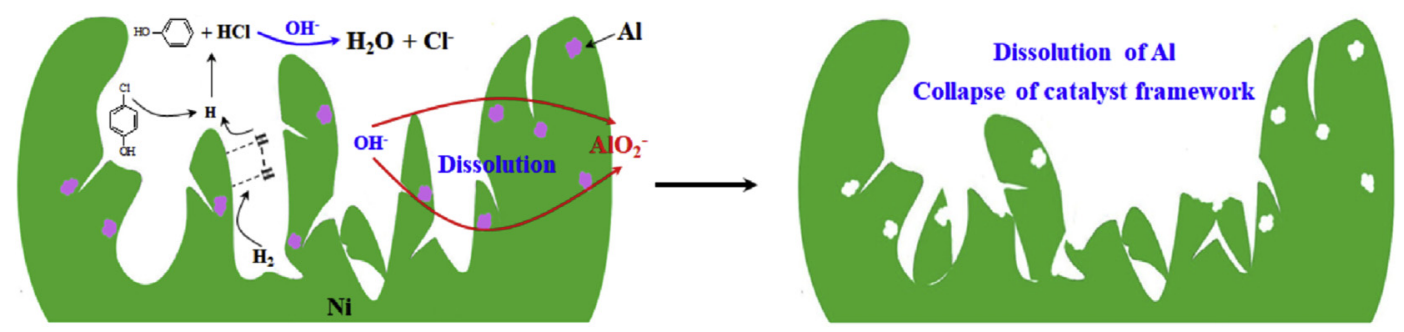

Scheme 2. Proposed mechanism for the effect of $\mathrm{NaOH} / \mathrm{Et}_{3} \mathrm{~N}$ amount on Raney Ni-catalyzed HDC of 4-chlorophenol.
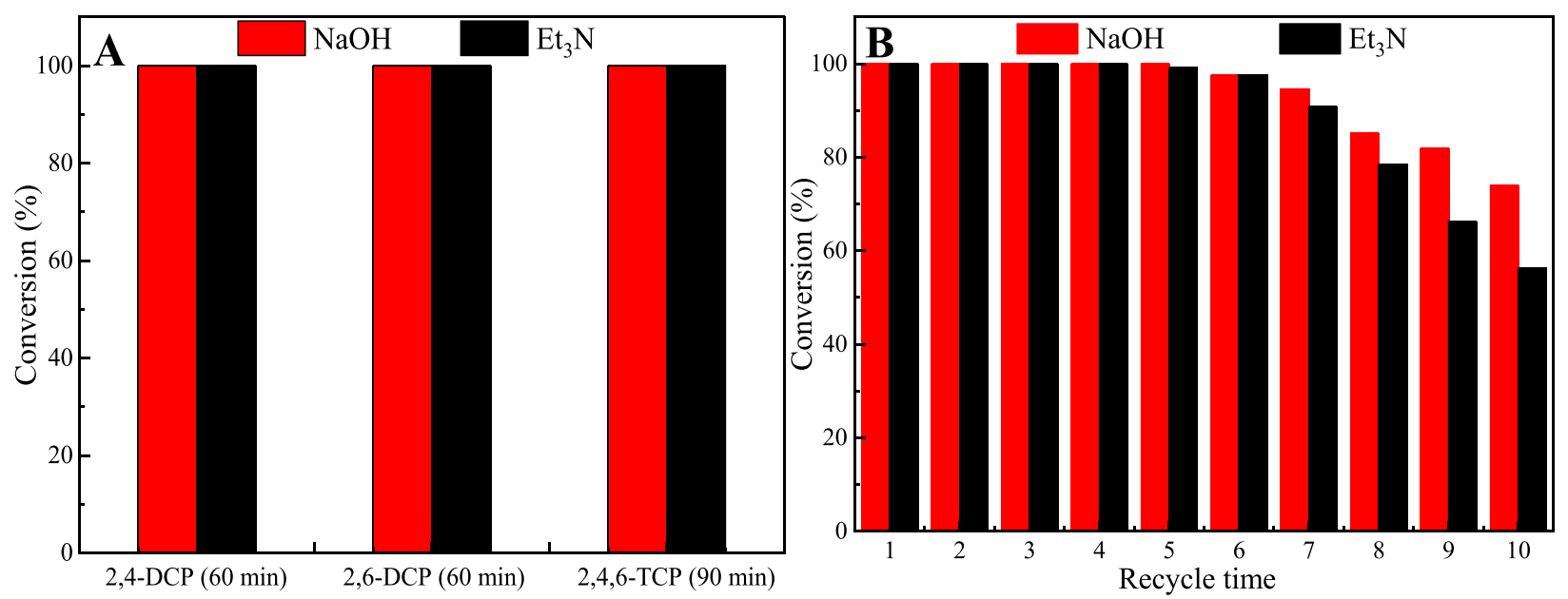

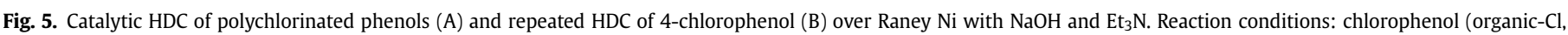
$6.20 \mathrm{mmol}$ ), Raney $\mathrm{Ni}(0.12 \mathrm{~g}), \mathrm{NaOH} / \mathrm{Et}_{3} \mathrm{~N}$ (6.85 mmol), $\mathrm{H}_{2}: 10 \mathrm{~mL} \mathrm{~min}^{-1}$.

on Raney Ni-catalyzed HDC reaction and clarified the mechanism of base promoted effect. It was found that bases significantly promoted Raney Ni-catalyzed HDC of chlorophenol, and strong inorganic bases $(\mathrm{NaOH}$ and $\mathrm{KOH})$ and $\mathrm{Et}_{3} \mathrm{~N}$ were more effective for the
HDC reaction. Moreover, the amount of strong inorganic bases and $\mathrm{Et}_{3} \mathrm{~N}$ has significant effect on the HDC reaction. The addition of various bases suppressed $\mathrm{HCl}$ corrosion to Raney $\mathrm{Ni}$, and decreased active phase $\mathrm{Ni}$ and $\mathrm{Al}$ leaching. Moreover, a stoichiometric amount 
of $\mathrm{NaOH} / \mathrm{Et}_{3} \mathrm{~N}$ could eliminated $\mathrm{HCl}$ corrosion to Raney $\mathrm{Ni}$, and prevented collapse of the catalyst framework resulted from dissolution of Al. Furthermore, the stoichiometric amount of $\mathrm{NaOH}$ was applicable to the excellent HDC of polychlorinated phenols over Raney $\mathrm{Ni}$, and the catalyst was stable after several recycles. From a practical viewpoint, the stoichiometric amount of $\mathrm{NaOH}$ is potentially available for the HDC of wastewater containing chlorophenols since it is cost efficiency and generally easy for practicality. Further investigation is in progress for the technical and economic feasibility of the base promoted HDC in wastewater containing chlorophenols, which is of environmental significance.

\section{Declaration of competing interest}

The authors declare no competing financial interest.

\section{CRediT authorship contribution statement}

Xuanxuan Ma: Investigation, Data curation, Formal analysis, Writing - original draft. Sujing Liu: Data curation, Formal analysis, Project administration. Ying Liu: Data curation, Supervision. Xiaoqiang Li: Formal analysis, Validation. Qing Li: Writing - review \& editing. Guodong Gu: Writing - review \& editing. Chuanhai Xia: Funding acquisition, Writing - review \& editing.

\section{Acknowledgement}

The authors gratefully appreciate financial support from the Natural Science Foundation of China (201976076), A Project of Shandong Province Higher Educational Science and Technology Program (J18KA096), Natural Science Foundation of Shandong Province of China (ZR2017BD029), State Key Laboratory of Environmental Chemistry and Ecotoxicology, and Research Center for Eco-Environmental Sciences, CAS (KF2017-12), Key Laboratory of Coastal Environmental Processes and Ecological Remediation, YICCAS (2018KFJJ07), and Cultivation Plan of Superior Discipline Talent Teams of Universities in Shandong Province: "the Coastal Resources and Environment team for Blue-Yellow Area".

\section{Appendix A. Supplementary data}

Supplementary data to this article can be found online at https://doi.org/10.1016/j.chemosphere.2019.125202.

\section{References}

Cheng, R., Zhou, W., Wang, J., Qi, D., Guo, L., Zhang, W., Qian, Y., 2010. Dechlorination of pentachlorophenol using nanoscale Fe/Ni particles: role of nano-Ni and its size effect. J. Hazard. Mater. 180, 79-85.

Cobo, M.I., Conesa, J.A., Montes de Correa, C., 2008. The effect of $\mathrm{NaOH}$ on the liquidphase hydrodechlorination of dioxins over $\mathrm{Pd} / \gamma-\mathrm{Al}_{2} \mathrm{O}_{3}$. J. Phys. Chem. A 112, 8715-8722.

de Pedro, Z.M., Diaz, E., Mohedano, A.F., Casas, J.A., Rodriguez, J.J., 2011. Compared activity and stability of $\mathrm{Pd} / \mathrm{Al}_{2} \mathrm{O}_{3}$ and $\mathrm{Pd} / \mathrm{AC}$ catalysts in 4-chlorophenol hydrodechlorination in different $\mathrm{pH}$ media. Appl. Catal. B Environ. 103, $128-135$.

Descorme, C., 2017. Catalytic wastewater treatment: oxidation and reduction processes. Recent studies on chlorophenols. Catal. Today 297, 324-334.

Duan, J., Zhu, H., Xu, F., Zhao, J., 2016. A new approach to 4-chlorophenol dechlorination on monometallic copper compared to its $\mathrm{Cu} / \mathrm{Fe}$ bimetallic system. Chem. Eng. J. 304, 282-288.

Ge, T., Han, J., Qi, Y., Gu, X., Ma, L., Zhang, C., Naeem, S., Huang, D., 2017. The toxic effects of chlorophenols and associated mechanisms in fish. Aquat. Toxicol. 184, 78-93.

Gómez-Quero, S., Cárdenas-Lizana, F., Keane, M.A., 2008. Effect of metal dispersion on the liquid-phase hydrodechlorination of 2,4-dichlorophenol over $\mathrm{Pd} / \mathrm{Al}_{2} \mathrm{O}_{3}$. Ind. Eng. Chem. Res. 47, 6841-6853.

Guan, X., Ghimire, A., Potter, P.M., Lomnicki, S.M., 2019. Role of $\mathrm{Fe}_{2} \mathrm{O}_{3}$ in fly ash surrogate on PCDD/Fs formation from 2-monochlorophenol. Chemosphere 226, 809-816.
Jadbabaei, N., Ye, T., Shuai, D., Zhang, H., 2017. Development of palladium-resin composites for catalytic hydrodechlorination of 4-chlorophenol. Appl. Catal. B Environ. 205, 576-586.

Keane, M.A., 2011. Supported transition metal catalysts for hydrodechlorination reactions. ChemCatChem 3, 800-821.

Kume, A., Monguchi, Y., Hattori, K., Nagase, H., Sajiki, H., 2008. Pd/C-catalyzed practical degradation of PCBs at room temperature. Appl. Catal. B Environ. 81, 274-282.

Li, C., Wang, Y., Chen, C., Fu, X., Cui, S., Lu, J., Liu, H., Li, W., 2019. Interactions between chlorophenols and peroxymonosulfate: $\mathrm{pH}$ dependency and reaction pathways. Sci. Total Environ. 664, 133-139.

Liu, Y., Yan, Z., Chen, R., Yu, Y., Chen, X., Zheng, X., Huang, X., 2019. 2,4Dichlorophenol removal from water using an electrochemical method improved by a composite molecularly imprinted membrane/bipolar membrane. J. Hazard. Mater. 377, 259-266.

Luo, J., Wang, Y., Cao, D., Xiao, K., Guo, T., Zhao, X., 2018. Enhanced photoelectrocatalytic degradation of 2,4-dichlorophenol by $\mathrm{TiO}_{2} / \mathrm{Ru}-\mathrm{IrO}_{2}$ bifacial electrode. Chem. Eng. J. 343, 69-77.

Ma, X., Liu, S., Liu, Y., Li, Q., Gu, G., Xia, C., 2018. New insights into the effect of base on the dechlorination of DDT in isopropanol-water over Pd/C catalyst under mild conditions. Chem. Eng. J. 351, 756-765.

Ma, X., Liu, Y., Li, X., Xu, J., Gu, G., Xia, C., 2015. Water: the most effective solvent for liquid-phase hydrodechlorination of chlorophenols over Raney Ni catalyst. Appl. Catal. B Environ. 165, 351-359.

Ma, X., Zhou, S., Yang, C., Liu, S., Bi, X., Xia, C., 2010. The influence of triethylamine on the hydrodechlorination reactivity of chlorophenols over Raney Ni catalyst. Catal. Commun. 12, 282-285.

Madannejad, S., Rashidi, A., Sadeghhassani, S., Shemirani, F., Ghasemy, E., 2018 Removal of 4-chlorophenol from water using different carbon nanostructures: a comparison study. J. Mol. Liq. 249, 877-885.

Munoz, M., Ponce, S., Zhang, G., Etzold, B.J.M., 2016. Size-controlled PtNi nanoparticles as highly efficient catalyst for hydrodechlorination reactions. Appl. Catal. B Environ. 192, 1-7.

Ordóñez, S., Vivas, B.P., Díez, F.V., 2010. Minimization of the deactivation of palladium catalysts in the hydrodechlorination of trichloroethylene in wastewaters. Appl. Catal. B Environ. 95, 288-296.

Peng, Y., Chen, J., Lu, S., Huang, J., Zhang, M., Buekens, A., Li, X., Yan, J., 2016. Chlorophenols in municipal solid waste incineration: a review. Chem. Eng. J 292, 398-414.

Pizarro, A.H., Molina, C.B., Munoz, M., de Pedro, Z.M., Menendez, N., Rodriguez, J.J., 2017. Combining HDC and CWPO for the removal of $p$-chloro-m-cresol from water under ambient-like conditions. Appl. Catal. B Environ. 216, 20-29.

Pizarro, A.H., Monsalvo, V.M., Molina, C.B., Mohedano, A.F., Rodriguez, J.J., 2015 Catalytic hydrodechlorination of $p$-chloro-m-cresol and 2,4,6-trichlorophenol with Pd and Rh supported on Al-pillared clays. Chem. Eng. J. 273, 363-370.

Rong, H., Cai, S., Niu, Z., Li, Y., 2013. Composition-dependent catalytic activity of bimetallic nanocrystals: AgPd-catalyzed hydrodechlorination of 4 chlorophenol. ACS Catal. 3, 1560-1563.

Shu, X., Yang, Q., Yao, F., Zhong, Y., Ren, W., Chen, F., Sun, J., Ma, Y., Fu, Z., Wang, D. Li, X., 2019. Electrocatalytic hydrodechlorination of 4-chlorophenol on Pd supported multi-walled carbon nanotubes particle electrodes. Chem. Eng. J. 358, 903-911.

Song, J., Zhao, Q., Guo, J., Yan, N., Chen, H., Sheng, F., Lin, Y., An, D., 2019. The microbial community responsible for dechlorination and benzene ring opening during anaerobic degradation of 2,4,6trichlorophenol. Sci. Total Environ. 651, $1368-1376$.

Urbano, F.J., Marinas, J.M., 2001. Hydrogenolysis of organohalogen compounds over palladium supported catalysts. J. Mol. Catal. A Chem. 173, 329-345.

Wu, B.-Z., Chen, H.-Y., Wang, S.J., Wai, C.M., Liao, W., Chiu, K., 2012. Reductive dechlorination for remediation of polychlorinated biphenyls. Chemosphere 88, 757-768.

Xia, C., Xu, J., Wu, W., Luo, Q., Chen, J., Zhang, Q., Liang, X., 2003. Catalytic hydrodechlorination of 2,4,4'-trichloro-2'-hydroxydiphenylether under mild conditions. Appl. Catal. B Environ. 45, 281-292.

Xiong, J., Ma, Y., Yang, W., Zhong, L., 2018. Rapid, highly efficient and stable catalytic hydrodechlorination of chlorophenols over novel Pd/CNTs-Ni foam composite catalyst in continuous-flow. J. Hazard. Mater. 355, 89-95.

Xu, F., Deng, S., Xu, J., Zhang, W., Wu, M., Wang, B., Huang, J., Yu, G., 2012. Highly active and stable $\mathrm{Ni}-\mathrm{Fe}$ bimetal prepared by ball milling for catalytic hydrodechlorination of 4-chlorophenol. Environ. Sci. Technol. 46, 4576-4582.

Yang, S., Zheng, D., Ren, T., Zhang, Y., Xin, J., 2017. Zero-valent aluminum for reductive removal of aqueous pollutants over a wide $\mathrm{pH}$ range: performance and mechanism especially at near-neutral pH. Water Res. 123, 704-714.

Yuan, G., Keane, M.A., 2004a. Liquid phase hydrodechlorination of chlorophenols over $\mathrm{Pd} / \mathrm{C}$ and $\mathrm{Pd} / \mathrm{Al}_{2} \mathrm{O}_{3}$ : a consideration of $\mathrm{HCl} /$ catalyst interactions and solution pH effects. Appl. Catal. B Environ. 52, 301-314.

Yuan, G., Keane, M.A., 2004b. Role of base addition in the liquid-phase hydrodechlorination of 2,4-dichlorophenol over $\mathrm{Pd} / \mathrm{Al}_{2} \mathrm{O}_{3}$ and $\mathrm{Pd} / \mathrm{C}$. J. Catal. 225, $510-522$.

Zhao, J., Chen, X., Wang, L., Xu, Y., Li, J., Li, Y., 2017. Effects of elevated 4-chloropheno loads on components of polysaccharides and proteins and toxicity in an activated sludge process. Chem. Eng. J. 330, 236-244.

Zhao, J., Li, Y., Chen, X., Li, Y., 2018. Effects of carbon sources on sludge performance and microbial community for 4-chlorophenol wastewater treatment in sequencing batch reactors. Bioresour. Technol. 255, 22-28. 
Zheng, K., Song, Y., Wang, X., Li, X., Mao, X., Wang, D., 2019. Understanding the electrode reaction process of dechlorination of 2,4-dichlorophenol over $\mathrm{Ni} / \mathrm{Fe}$ nanoparticles: effect of $\mathrm{pH}$ and 2,4-dichlorophenol concentration. J. Environ. Sci. $84,13-20$.

Zhou, J., Chen, H., Chen, Q., Huang, Z., 2016. Bimetallic Au-decorated Pd catalyst for the liquid phase hydrodechlorination of 2,4-dichlorophenol. Appl. Surf. Sci. 387, $588-594$.

Zhou, P., Zhang, J., Zhang, Y., Zhang, G., Li, W., Wei, C., Liang, J., Liu, Y., Shu, S., 2018 Degradation of 2,4-dichlorophenol by activating persulfate and peroxomonosulfate using micron or nanoscale zero-valent copper. J. Hazard. Mater. 344, 1209-1219.

Zinovyev, S., Shelepchikov, A., Tundo, P., 2007. Design of new systems for transfer hydrogenolysis of polychlorinated aromatics with 2-propanol using a Raney nickel catalyst. Appl. Catal. B Environ. 72, 289-298.

Zinovyev, S., Tundo, P., 2007. On the promoting effect by quaternary ammonium salts in the multiphase hydrodechlorination with hydrogen gas on Raney nickel catalyst. Appl. Catal. B Environ. 75, 124-128. 